\title{
Pediatric Acute-onset Neuropsychiatric Syndrome and Mycoplasma Pneu- moniae Infection: A Case Report Analysis with a Metabolomics Approach
}

\author{
Cristina Piras ${ }^{1}$, Roberta Pintus ${ }^{2}$, Dario Pruna ${ }^{3}$, Angelica Dessì ${ }^{2}$, Luigi Atzori ${ }^{1}$ and Vassilios Fanos ${ }^{2, *}$ \\ ${ }^{I}$ Department of Biomedical Sciences, University of Cagliari, Cagliari, Italy; ${ }^{2}$ Department of Surgical Sciences, Neonatal \\ Intensive Care Unit, Puericulture Institute and Neonatal Section, Azienda Ospedaliera Universitaria, Cagliari, Italy; \\ ${ }^{3}$ Pediatric Neurology and Epileptology Unit, Brotzu Hospital Trust, Cagliari, Italy
}

\begin{abstract}
Pediatric Acute-onset Neuropsychiatric Syndrome (PANS) is a clinical condition characterized by a sudden and dramatic obsessive-compulsive disorder with a recommended postinfectious immune-mediated etiology. This condition is accompanied by an extensive series of relatively serious neuropsychiatric symptoms. The diagnosis of PANS is made by "exclusion", as the individual PANS symptoms overlap with a multiplicity of psychiatric disorders with the onset in childhood. A number of researchers accumulated evidence to support the hypothesis that PANS was closely associated with a number of infections.

In the last decade, metabolomics played an essential role in improving the knowledge of complex biological systems and identifying potential new biomarkers as indicators of pathological progressions or pharmacologic responses to therapy. The metabolome is considered the most predictive phenotype, capable of recognizing epigenetic differences, reflecting more closely the clinical reality at any given moment and thus providing extremely dynamic data. In the present work, the most recent hypothesis and suggested mechanisms of this condition are reviewed and the case of a 10 year-old girl with PANS is described, before and after clarithromycin treatment. The main results of this case report are discussed from a metabolomics point of view. The alteration of several metabolic pathways concerning the microbial activity highlights the possible role of the microbiome in the development of PANS. Furthermore, different metabolic perturbations at the level of protein biosynthesis, energy and amino acid metabolisms are observed and discussed. Based on our observations, it is believed that metabolomics is a promising technology to unravel the mysteries of PANS in the near future.
\end{abstract}

Received: August 06, 2019 Revised: September 26, 2019 Accepted: October 02, 2019

DOI:

DOI: $10.2174 / 1573396315666191022102925$

Keywords: Pediatric Acute-onset Neuropsychiatric Syndrome (PANS), metabolomics, Proton Nuclear Magnetic Resonance $\left({ }^{1} \mathrm{H}-\mathrm{NMR}\right)$, mycoplasma pneumoniae, urine.

\section{INTRODUCTION}

PANS is a clinical condition characterized by the sudden and dramatic onset of obsessive-compulsive disorder (OCD) with recommended post-infectious immune-mediated etiology [1]. This condition is accompanied by an extensive series of relatively serious neuropsychiatric symptoms: separation anxiety; irritability, aggression and/or severely oppositional behaviors; emotional liability and/or depression; sensory or motor abnormalities with choreiform finger movements; academic decline related to attention and memory deficit; sleep disturbances, severely restricted food intake, urinary frequency and enuresis [2, 3]. The diagnosis of PANS is made by "exclusion", as the individual PANS

*Address correspondence to this author at the Department of Surgical Sciences, Neonatal Intensive Care Unit, Puericulture Institute and Neonatal Section, Azienda Ospedaliera Universitaria, Cagliari, Italy; E-mail: vafanos@tin.it symptoms overlap with a multiplicity of psychiatric disorders with the onset in childhood, such as schizophrenia, depression, ADHD (Attention Deficit Hyperactivity Disorder), Tourette's syndrome and bipolar disorder. However, the abrupt and simultaneous onset of these symptoms makes it possible to differentiate PANS from other neurodevelopmental disorders [4]. It is therefore important, in PANS suspicion, to be able to obtain a complete medical and psychiatric history, as well as carry out a thorough physical examination accompanied by laboratory tests [4]. Indeed, PANS is characterized by a large number of related disorders with multiple etiology, ranging from autoimmune or autoinflammatory diseases to immunodeficiency syndromes and recurrent infections [1-4]. In particular, in the second half of 1990 s, different investigators at the National Institute of Mental Health (NIMH) observed that the abrupt and simultaneous onset of OCD disorders was associated with a viral or bacterial infection, such as varicella, influenza, and infections from Streptococcus pyogenes, Mycoplasma pneumo- 
niae, Group A Streptococcus, Epstein Barr and Borrelia burgdorferi $[5,6]$. Allen et al., in 1995, highlighted how in some patients the infections by micro-organisms (in particular from Group A $\beta$-hemolytic Streptococcus) can trigger autoimmune responses, causing or exacerbating the childhood-onset of OCD or tic disorders (including Tourette's syndrome) through a process analogous to Sydenham's chorea [6].

Subsequent studies on a larger population confirmed that positivity to Group A $\beta$-hemolytic Streptococcus infection was present in $60-75 \%$ of the children affected by OCD. The particularly unique clinical features of the case studies served as a basis for the diagnostic criteria for the defined subgroup, PANDAS (Pediatric autoimmune neuropsychiatric disorder associated with streptococcus) $[6,7]$. Over the time, a number of researchers accumulated more evidence to support the hypothesis that PANS and PANDAS were closely associated with a variety of infections [8, 9], including $M y$ coplasma pneumoniae $[10,11]$. Alternatively, in the absence of the reported infection, this syndrome is presumed to result from a variety of disease mechanisms with multiple etiologies (neuroinflammatory, toxic, endocrine, metabolic and environmental disorders) $[12,13]$.

\section{INFECTION BY NON-STREPTOCOCCAL BAC- TERIA}

Although the primary focus has been on streptococcal infections [14, 15], a variety of putative infections have been suggested to determine the clinical picture of PANS. The most commonly observed previous infections seem to be of the upper respiratory tract, including rhinosinusitis, pharyngitis, or bronchitis.

Mycoplasma pneumoniae is a bacterial pathogen that causes frequent infections every year in the upper and lower respiratory tract in children as well as in adults. It is primarily an extracellular pathogen that depends on a close hostcell interaction for survival; nevertheless in some cases, it is able to penetrate the cell membrane of the host and invade the cells $[16,10]$. In particular, this bacterium is known to cause various types of extra-pulmonary symptoms involving almost all organs of the human body, including the central nervous system (acute cerebellar ataxia, thalamic necrosis, and early onset encephalitis) $[17,18]$. In fact, it has been revealed that the cell membrane of Mycoplasma pneumoniae contains some lipoproteins considered to be potent inducers of cytokines, equivalent to bacterial lipopolysaccharide and its cytoplasm containing strong immunogenic molecules, such as glycolipids and glycoproteins, which can stimulate autoimmunity through their molecular mimics of various components of human cells, particularly in the brain [10, 1921]. In 2016, Narita indicated three possible pathomechanisms, direct, indirect type and vascular occlusion type, concerning the extra-pulmonary manifestations due to M. pneumoniae infection [18]. The "direct type" involves the damage of the nervous tissue strictly due to the local activity of Mycoplasma pneumoniae, while the "indirect type" implies the absence of the bacterium at the inflammation site where mechanisms, based on autoimmunity or formation of immune complexes, can play an important role. Finally, the third type of mechanism involves a type of vascular occlu- sion in which the blood flow obstruction is directly or indirectly induced by the bacteria. The literature studies in the last ten years report the possible role of Mycoplasma pneumoniae in neurological manifestations, including encephalitis $[21,22]$, acute disseminated encephalomyelitis [23, 24], cerebellar disease [25, 26], myasthenia gravis [27] and two cases of transient Parkinsonism in association with Mycoplasma pneumoniae infections [28]. Thus, even Mycoplasma pneumoniae is a suspected trigger of PANS, although no single microbe, apart from Group A $\beta$-hemolytic Streptococcus, has yet been consistently associated with the onset of PANS. Muller et al., in 2000, indicated an association between Mycoplasma pneumoniae infection and Tourette's syndrome $[10,29]$. In this study, elevated antibody titers against Mycoplasma pneumoniae were found to be significantly higher in patients with Tourette syndrome than the controls, suggesting a role of Mycoplasma pneumoniae in a subgroup of Tourette syndrome patients. They described two cases with Tourette's syndrome involving Mycoplasma pneumoniae infection where inflammatory signs, immunological response, detection of the DNA of Mycoplasma pneumoniae in the cerebrospinal fluid, and prompt improvement of the symptoms during antibiotic therapy demonstrated how the neuropsychiatric symptoms were closely linked to the Mycoplasma pneumoniae infection.

As in the case of neurodevelopmental disorders, such as Sydenham's chorea and Tourette's syndrome, a mechanism of molecular mimicry is also hypothesized for PANS and PANDAS. The different theories proposed concern the possibility that serum antibodies produced against infectious and non-infectious agents cross the blood-brain barrier and crossreact with neuronal antigens [30-33]. These antibodies then cause dysregulation of the basal ganglia functions, producing a multiplicity of neurological and psychiatric symptoms. Anti-neuronal antibodies observed are anti-lysoganglioside, anti-tubulin, and anti-dopamine D1 and D2 receptor antibodies. In Sydenham's chorea, monoclonal antibodies showed specificity for mammalian lysoganglioside GM1 (a CSN ganglioside that influences neuronal signal transduction) and $\mathrm{N}$-acetyl- $\beta$-D-glucosamine, the immunodominant epitope of the Group A streptococcus (GAS) carbohydrate [34]. These antibodies were present in both the serum and cerebrospinal fluid of patients with acute Sydenham's chorea. Chorea antibodies were able to target the surface of human neuronal cells in vitro, with specific induction of calcium/calmodulindependent protein kinase II, a protein kinase involved in multiple signaling cascades. Further investigations revealed the presence of basal ganglia antibodies in the serum of PANDAS patients at significantly lower concentrations than Sydenham's chorea patients [32].

The autoimmune pathophysiology of PANS or PANDAS depends not only on the presence of neuronal antibodies but also on the action of neuroactive cytokines, IL-17A, IFN- $\gamma$, as inflammatory mediators [35-38]. Dileepan et al., in 2016, identified GAS-specific T helper 17 cells in tonsils of humans naturally exposed to the GAS, prompting us to explore whether GAS-specific CD4+T lymphocytes home the mouse brain following infection. In mice, repeated intranasal GAS inoculation promoted the migration of GAS-specific Th17 cells from nasal-associated lymphoid tissues into the brain. IL-17A and other cytokines produced by $\mathrm{T}$ helper 17 cells 
activate microglia and induce blood-brain barrier breakdown, resulting in extravasation of antibodies and further circulation of $T$ cells into the brain. Autoantibodies induced by bacteria then target mimetic brain antigens, such as dopamine receptors, to induce abnormal motor and/or behavioral changes [37, 38]. A similar mechanism could also be hypothesized for neuropathologies induced by Mycoplasma pneumoniae.

Nowadays, with current standard radiological or biochemical techniques, it is not possible to establish the specific cause of the symptoms observed in PANS patients. It is only possible to make a hypothesis after the histopathological analysis of the postmortem brain tissues of these patients. Recently, there has been a strong interest in the relationship between the intestinal microbiota and the brain function, stressing the relevance of the so-called gut-brain axis [39]. The modifications in the microbiome due to diet, stress or antibiotic treatment are considered to be involved in various pathological conditions, including inflammatory bowel disease, metabolic disorders, allergies and neurological disorders (e.g., anxiety, depression, schizophrenia, and autism) [40-45]. In fact, a condition of inflammation in the gastrointestinal tract can, through the release of cytokines and neurotransmitters, stress the microbiome and increase the intestinal permeability, allowing bacteria, bacterial products/molecules, or inflammatory cytokines, to filter through the submucosa into the systemic circulation. This is only a part of the complex phenomenon known as "leaky gut syndrome" [39]. Once they reach the systemic circulation, these products can eventually reach the brain by crossing the blood-brain barrier, or they can modify the permeability of this barrier as well, and ultimately influence the brain function [46]. Quagliariello et al., in 2018, performed a study on gut microbiota profiling in children with PANS and PANS associated with streptococcal infections compared to control subjects [47]. PANS/PANDAS children were characterized by a strong increase in Bacteroidetes. In particular, the investigator identified Bacteroides, Odoribacter, and Oscillospira as potential microbial biomarkers. Moreover, the children with PANS/PANDAS exhibited increased activation of several pathways concerning the modulation of the antibody response to inflammation within the gut as well as decreased activation of the pathways involved in brain function, such as short-chain fatty acids, D-alanine and tyrosine metabolism, and the dopamine pathway.

\section{METABOLOMICS: THE "NEW CLINICAL BIO- CHEMISTRY" IN THE UNDERSTANDING OF PEDI- ATRIC ACUTE-ONSET NEUROPSYCHIATRIC SYN- DROME}

The data reported so far in the literature identify PANS only on the basis of a number of behavioral conditions without possible biological markers that can clearly distinguish PANS from other similar neuropsychiatric disorders and confirm the hypothesis of inflammatory mechanisms.

In the last decade, different 'omics' disciplines, such as genomics, transcriptomics, proteomics and metabolomics, played an essential role in improving the knowledge of complex biological systems and identifying potential new biomarkers as indicator of normal biological courses, pathologi- cal progressions, or pharmacologic responses to a therapeutic intervention [48-50]. In particular, metabolomics, unlike other 'omics' disciplines, provides a 'phenotypic snapshot' of a cell, tissue or organism, reflecting more closely the clinical reality at any given time. This could improve the understanding of physiopathological mechanisms, the identification of new profiles to classify a pathological condition and indication of the possible targets of the therapy [51]. Metabolomics identifies and quantifies the "metabolome". The term "metabolome" was coined, in a way similar to that of the genome and proteome, in 1998 by Oliver et al. [52] to designate a dynamic set of low molecular weight molecules $(<1000 \mathrm{Da})$, including amino acids, oligopeptides, sugars, steroids, biliary acids, simple and complex fatty acids and intermediate compounds of many biochemical pathways in an organism. The metabolome is considered the most predictive phenotype, capable of recognizing epigenetic differences, reflecting more closely the clinical reality at any given moment and thus providing extremely dynamic data. In fact, the metabolome can vary in accordance with the physiological or pathological state of cells, tissues, organs or organisms. In metabolomics, the choice of the biological material, such as biofluids (plasma, blood, urine, serum, cerebrospinal fluid, liquor, and saliva) or tissue, and the analytical methods of investigation (nuclear magnetic resonance spectroscopy and mass spectrometry) are very important and depend on the objective of the study. Metabolomic studies conducted on pediatric patients predominantly used urine as a biofluid because its collection is easy and non-invasive and carries important diagnostic information. A large number of metabolites characterize the urine, including products or intermediates of different metabolic processes. Metabolomics is considered a 'window into the organism' that monitors the entire metabolism and its biochemical profile is the result of a combination of factors, such as genotype, physiological state, state of health, nutrition and the environment [51].

In recent years, different metabolomic studies have been performed in order to better characterize the mechanisms underlying neurological disorders in the pediatric population, such as the autism spectrum disorders, and to identify new diagnostic biomarkers that can support the clinical diagnosis of the pathology. Some of these studies were performed by our group by comparing autistic children with their healthy siblings. These patients showed altered concentrations of several organic acids, sugars, and metabolites of bacterial origin [53-57].

As previously stated, the diagnosis of PANS is still under debate and not well defined. Therefore, it is important to better understand the pathogenic mechanisms of PANS and to identify disease-specific biomarkers. Metabolomics, in recent years, has contributed in improving the understanding of different neurological diseases and identified potential biomarkers of the disease [58-61].

Given the severe and devastating nature of the symptoms and the effects on family and children, the understanding of the biological basis of this syndrome and the identification of evidence-based and effective therapies are necessary. The aim of this case report is to suggest a study on the metabolome in the field of PANS in order to define its pathogenesis and characterize possible biomarkers. 


\section{CASE REPORT}

\subsection{Clinical History}

A 7-year-old girl suddenly had recurrent episodes of vomiting in the morning which persisted for more than a month. A gastroenterological consultation was immediately requested and suggested a situation of nervous gastritis. She then began to show early symptoms of OCD, like drinking and washing continuously, accompanied by sporadic attacks of anger with sudden screaming and cries. Meanwhile, without any relevant change in the diet, the child gained almost $10 \mathrm{~kg}$ of body weight in a few weeks. After 2 months of the first sudden episode, the earliest motor abnormalities of upper and lower limbs and eyes also arose. No impairment in school performance was reported, however, her handwriting worsened. The girl was subjected to repeated medical checks, and stress was diagnosed as a major factor. The symptoms persisted moderately for about 3 years, which suddenly increased in intensity with OCD, tics, and motor anomalies and increasingly severe choreiform finger movements. The psychiatric department was consulted for her symptoms and she was initially diagnosed with Tourette's syndrome. Psychological support, behavioral and drug therapy were suggested. Drugs were not prescribed. The Yale Global Tic Severity Scale (YGTSS) index was calculated to be 40 , with a marked impact on daily activity and social relationships. After a year, given the persistence of the symptoms, possible PANDAS was suggested. During different clinical tests, amoxicillin and clavulanic acid were administered for 4 weeks, 2 times per day and then substituted with penicillin $\mathrm{G}$ benzathine for 18 days and ibuprofen as needed. The symptomatology after therapy did not improve. OCD symptoms, tics, and choreic movements persisted. Strongly opposing aggressiveness and behavior, depression, psychosis, and auditory hallucinations appeared.

Finally, after a positive test for Mycoplasma pneumoniae, clarithromycin was administered with probiotics. After 5 days of the antibiotic, the OCD symptoms decreased with normal walking without compulsions, absence of the fear of physical contact, good mood, good handwriting, and good learning speed. After 10 days of the antibiotic, the patient showed a marked reduction in symptoms, which almost disappeared. At that time, the YGTSS index was 18.

Urine samples for metabolomics analysis were collected in the presence of neurological symptoms and after 10 days of the clarithromycin treatment when the symptoms were significantly improved.

\subsection{Preparation of Urine Samples for ${ }^{1}$ H-NMR Analysis}

$800 \mu \mathrm{L}$ aliquot of urine was transferred into an Eppendorf tube together with $8 \mu \mathrm{L}$ of a $1 \%$ aqueous solution of $\mathrm{NaN}_{3}$ to inhibit bacteria growth and stored at $-80{ }^{\circ} \mathrm{C}$. Before the analysis, the sample was centrifuged at $12000 \mathrm{~g}$ for 10 min at $4{ }^{\circ} \mathrm{C}$ to remove some solid particles. Then, $630 \mu \mathrm{L}$ of the supernatant solution was mixed with $70 \mu \mathrm{L}$ of potassium phosphate buffer in $\mathrm{D} 2 \mathrm{O}(1.5 \mathrm{M}, \mathrm{pH} 7.4)$ containing sodium 3-trimethylsilyl-propionate-2,2,3,3,-d4 (TSP) as an internal standard with a final concentration of $1 \mathrm{mM}(98$ atom\% D, Sigma-Aldrich, Milan). An aliquot of $650 \mu \mathrm{L}$ was transferred to 5-mm NMR glass tubes for ${ }^{1} \mathrm{H}-\mathrm{NMR}$ measurement.

\subsection{Data Acquisition}

NMR analysis was carried out using a Varian UNITY INOVA 500 spectrometer operating at $499.839 \mathrm{MHz}$ for proton and equipped with a $5 \mathrm{~mm}$ double resonance probe (Agilent Technologies, CA, USA). ${ }^{1} \mathrm{H}-\mathrm{NMR}$ spectra were acquired using a standard pulse sequence (1D NOESY, One Dimensional Nuclear Overhauser Effect Spectroscopy) with presaturation during relaxation and mixing time for water suppression, at $300 \mathrm{~K}$ with a spectral width of $6000 \mathrm{~Hz}$, an acquisition time of $2 \mathrm{~s}$, a relaxation delay of $3 \mathrm{~s}$, a mixing time of $0.1 \mathrm{~s}$ and 256 scans. ${ }^{1} \mathrm{H}-\mathrm{NMR}$ spectra were imported in an ACDLab Processor Academic Edition (Advanced Chemistry Development, 12.01, 2010) and preprocessed with a line broadening of $0.5 \mathrm{~Hz}$, zero-filled to $64 \mathrm{~K}$, and Fourier transformed. Spectra were manually phased and baseline corrected and chemical shifts referenced internally to TSP. All the identified compounds were quantified by using the Chenomx NMR Suite 7.1 (Chenomx Inc., Edmonton, Alberta, Canada). This software provides a comprehensive database of metabolites and their signals, consisting of Lorentzian peaks that can be used for manual deconvolution. The processing of the NMR data (i.e., phase and baseline correction) is known to have a considerable impact on the accuracy of peak area integration, with relative uncertainty as high as $11 \%$ [62]. Therefore, a $20 \%$ measurement uncertainty was considered in order to identify relevant changes in the concentration of the metabolites before and after drug therapy.

\subsection{Pathway Analysis}

Metabolic pathways were generated by using MetaboAnalyst 3.0 (www.metaboanalyst.ca). MetaboAnalyst 3.0 is an integrated web-based platform for the comprehensive analysis and interpretation of metabolomics data [63].

\section{RESULTS}

In Fig. (1), the ${ }^{1} \mathrm{H}$ NMR spectrum of the urine sample 1) before and 2) after antibiotic therapy is shown. A large number of partly overlapping peaks characterized each ${ }^{1} \mathrm{H}$ NMR spectrum, reflecting the different metabolites present in the urine. Metabolites were identified based on literature information and by using authentic databases, such as the Human Metabolome Database (HMDB, http://www.hmdb. ca) and the $500 \mathrm{MHz}$ library from Chenomx NMR suite7.1. The spectra can be divided into two distinct spectral regions. The region from 0.6 to $4.7 \mathrm{ppm}$ (Fig. 1A) contains signals from free amino acids, organic acids, osmolytes, while the spectral portion between 6.4, and 9.6 ppm (Fig. 1B) is characterized by signals from aromatic metabolites. The graphs in Fig. (2) show only those metabolites with a variation in the concentration $>20 \%$ by comparing the metabolites in the urine before and after drug therapy. The urine sample after drug therapy exhibited decreased content of homoserine, glycolate, glutamine, ethanolamine, hippurate, trigonelline, formate, cis-aconitate, valine, methylamine and dimethylguanidine, and an increased content of creatine-phosphate, proline, histidine, lysine, trimethylamine $\mathrm{N}$-oxide, phenylalanine, methyl-histidine, ethanol, imidazole, methylsuccinate, 3-methyloxovalerate, tryptophan, pyruvate, isoleucine, riboflavin, 1-methylnicotinamide and pyroglutamate. The metabolic pathways analysis, conducted 

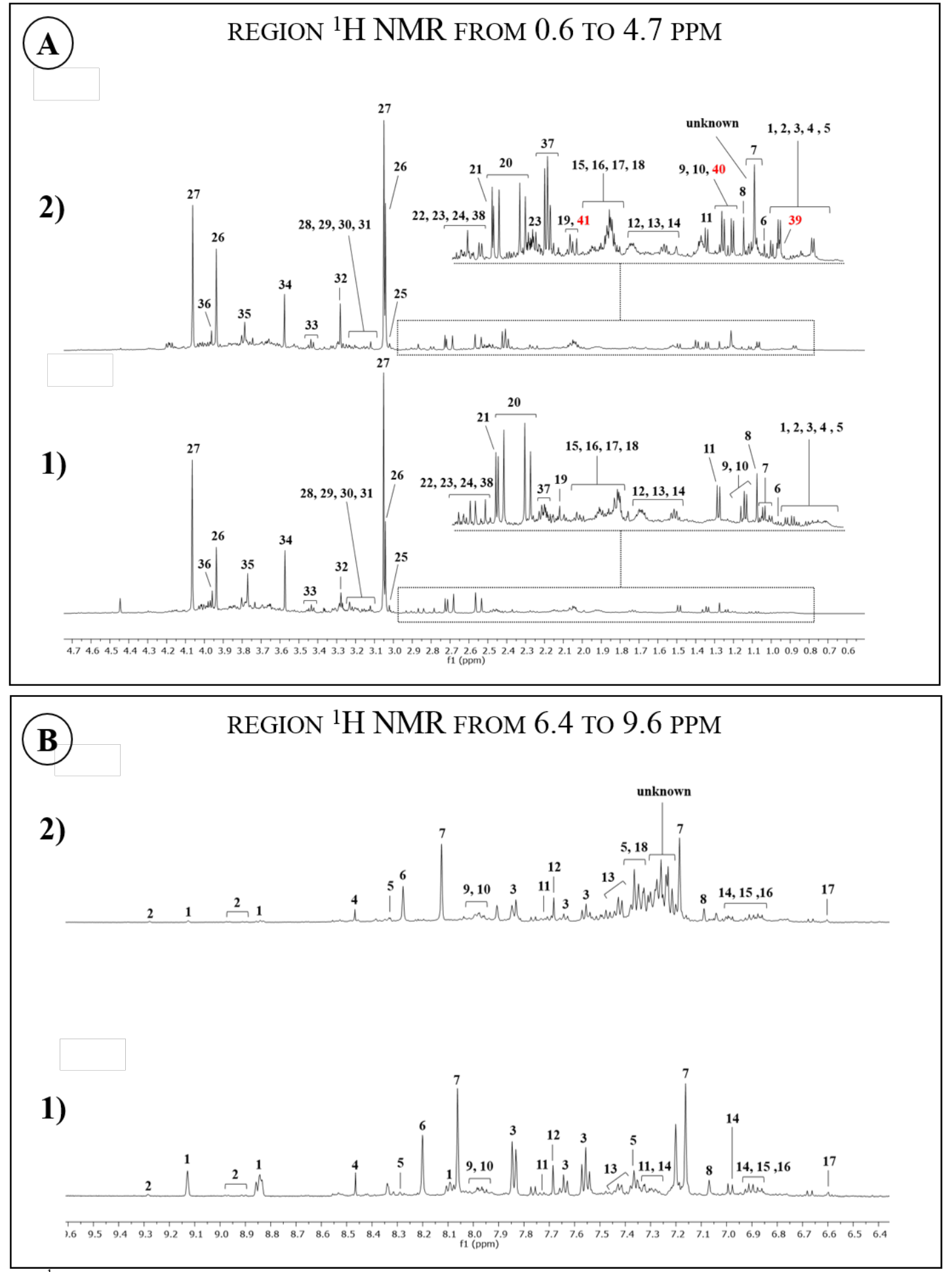

Fig. (1). $500 \mathrm{MHz}{ }^{1} \mathrm{H}-\mathrm{NMR}$ spectrum of urine obtained from 1) before and 2) after drug therapy.

PeAKs of the Region from 0.6 TO 4.7 PPM (A): 1) 3-Methyl-2-oxovalerate, 2) 2-Hydroxyvalerate, 3) Isoleucine, 4) Valine, 5) Methylsuccinate, 6) Ethanol, 7) Fucose, 8) 3-Hydroxyisovalerate, 9) Lactate, 10) Threonine, 11) Alanine, 12) Lysine, 13) Ornithine, 14) Acetate, 15) Homoserine, 16) Proline, 17) Glutamate, 18) Glutamine, 19) Pyruvate, 20) Citrate, 21) Dimethylamine, 22) Asparagine, 23) Trimethylamine, 24) Dimethylglycine, 25) Creatine, 26) Creatine phosphate, 27) Creatinine, 28) cis-Aconitate, 29) Malonate, 30) Ethanolamine, 31) Ophosphocholine, 32) Trimethylamine N-oxide, 33) Taurine, 34) Glycine, 35) Guanidoacetate, 36) Glycolate, 37) Pyroglutamate, 38) Dimethylguanidine, 39)* 2-Methylglutarate, 40$)^{*}$ 2-Phenylpropionate, 41$)^{*}$ Acetoacetate $(*$ the red number indicates the metabolites present only in the urine sample after drug therapy).

PeAKS OF THE REgiOn FROM 6.4 TO 9.6 PPM (B): 1) Trigonelline, 2) 1-methylnicotinamide, 3) Hippurate, 4) Formate, 5) Imidazole, 6) Hypoxanthine, 7) Histidine, 8) n-Methylhistidine, 9) Xanthine, 10) Riboflavin, 11) Tryptophan, 12) T-Methylhistidine, 13) Phenylalanine, 14) 3hydroxymandelate, 15) Tyrosine, 16) Kynurenine, 17) Trans-Aconitate, 18) 2-Phenylpropionate. 


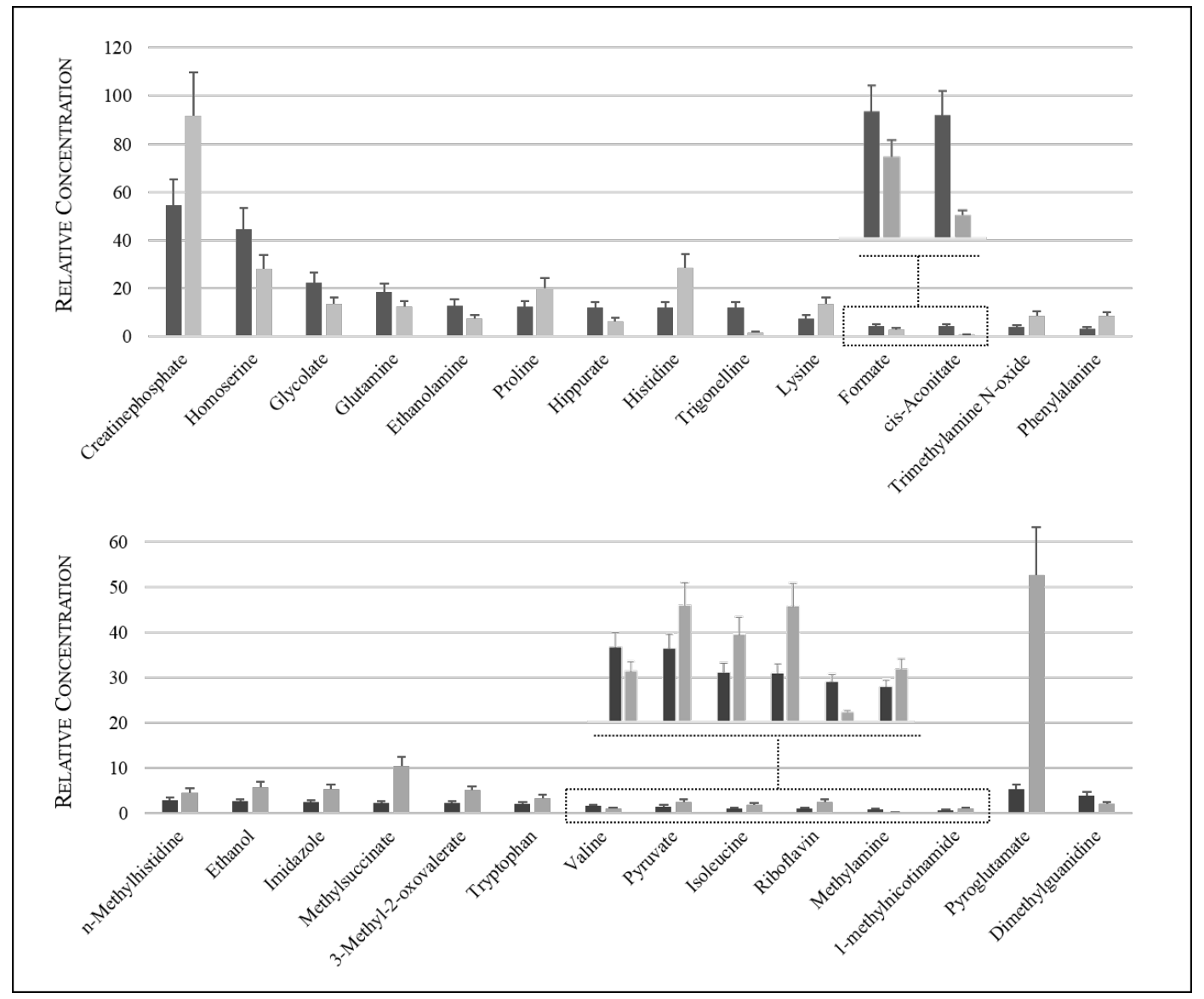

Fig. (2). A vertical bar plot shows progressive changes of the metabolites relative concentration on urine samples before (dark grey) and after drug therapy (light grey). The error bar represents a $20 \%$ uncertainty.
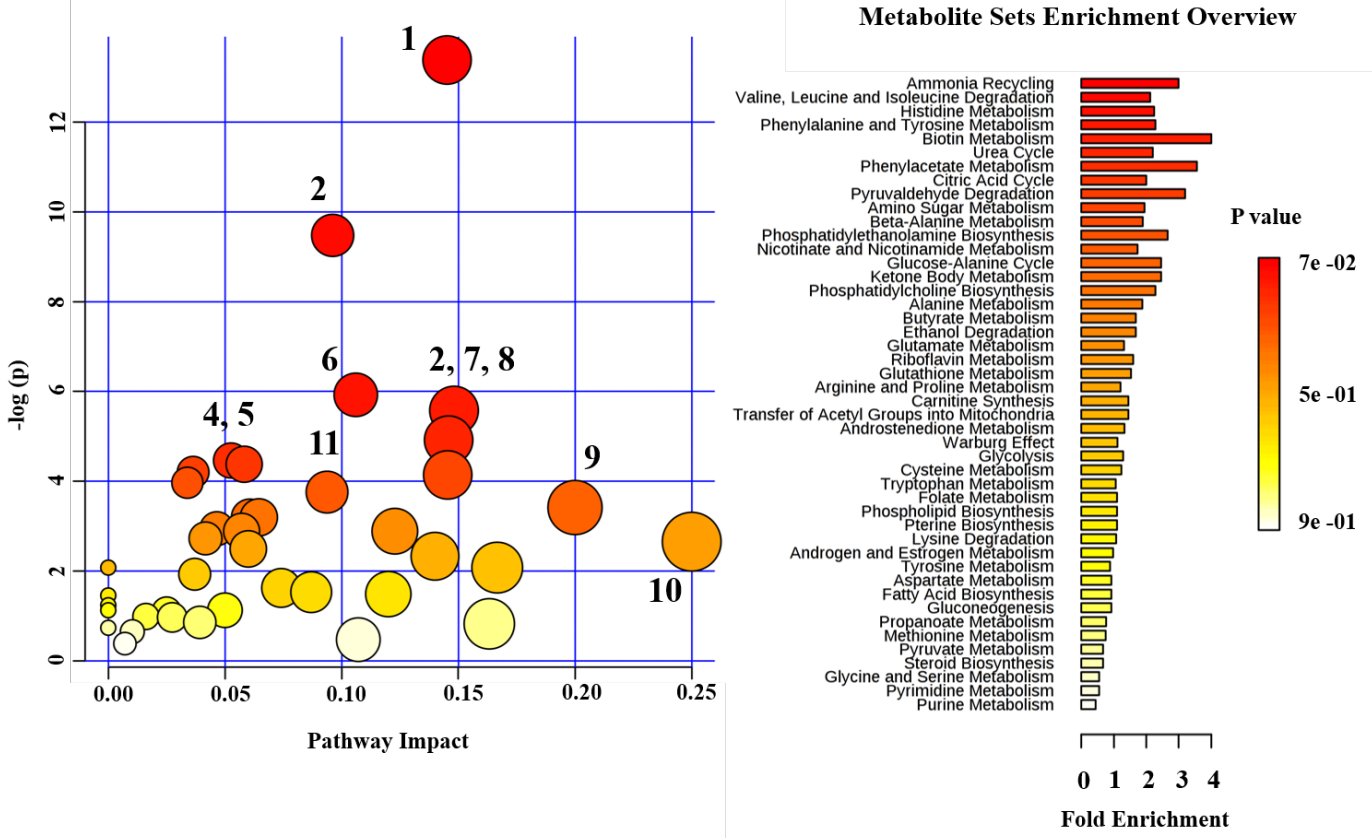

Fig. (3). Metabolic pathway analysis carried out by using all metabolites significantly changed in the urine sample after drug therapy. Metabolic pathways are arranged according to the scores from enrichment analysis (-log (p)) and topology analysis (pathway impact). The point color is based on its p-value and the point radius is determined based on their pathway impact values. Pathway: 1) Aminoacyl-tRNA biosynthesis; 2) Nitrogen metabolism; 3) Methane metabolism; 4) Arginine and proline metabolism; 5) Glycine, serine and threonine metabolism; 6) Glyoxylate and dicarboxylate metabolism; 7) Valine, leucine and isoleucine biosynthesis; 8) Phenylalanine metabolism; 9) Alanine, aspartate and glutamate metabolism; 10) Synthesis and degradation of ketone bodies, 11) Citrate cycle (TCA cycle). 
using the metabolites increased or decreased after drug therapy, highlighted several altered metabolic pathways, such as aminoacyl-tRNA biosynthesis, nitrogen metabolism, methane metabolism, free amino acids metabolism, glyoxylate and dicarboxylate metabolism, glutamate metabolism, synthesis and degradation of ketone bodies and citrate cycle (Fig. 3).

\section{DISCUSSION}

Pediatric acute-onset neuropsychiatric syndrome is characterized by a broad clinical spectrum of neuropsychiatric comorbidities, potentially triggered by the infections by microorganisms and/or eating disorders $[2,64]$. The present case-report, using a ${ }^{1} \mathrm{H}-\mathrm{NMR}$ based approach, showed a different metabolomics profile in the urine before and after drug treatment. The drug treatment consisted of an antibiotic therapy based on macrolide (clarithromycin) for the infection by Mycoplasma pneumoniae. After the antibiotic treatment, the patient showed a marked improvement in the obsessivecompulsive disorder (and/or tic disorders) and motoric hyperactivity (including muscle dystonia). Several authors reported the possibility of a strong link between the common infectious agents, such as viruses or bacteria, and neurological disorders [29, 65-67]. In particular, Ercan et al. published a case very similar to the one described in this study, discussing a 5.5-year-old Mycoplasma pneumoniae positive child. The authors emphasized that the onset of the symptoms was associated with the mycoplasma pneumonia infection, and after the third day of antibiotic therapy with clarithromycin, the obsessive-compulsive symptoms and aggressive attitude disappeared completely. In our case study, the improvement was limited to the period of the therapy. The analysis of the pathways highlights the alteration in the nitrogen metabolism, indicating the presence of a microbial activity despite antibiotic treatment. In fact, NMR spectrum analysis showed an alteration of some metabolites, such as pyruvate, formate, and ethanol, as well as some ketogenic amino acids, used by different bacterial cells as an ATP source $[68,69]$. Several authors reported the ability of $M y$ coplasma pneumoniae to persist even after several days of treatment, due to a mutation in the 23S rRNA gene in some Mycoplasma pneumoniae strains [70, 71]. The transitory improvement of the neurological symptoms could be due to the partial resolution of mycoplasma pneumonia infection, and probably due to some immunomodulatory characteristics of macrolides independent of their known antimicrobial properties [72-74]. Experimental evidence highlighted a pathophysiological relationship between inflammation and neuropsychiatric disorders. Some authors suggested a form of autoimmunity in a genetically susceptible host similar to Sydenham chorea, in which antibodies produced against bacterial proteins cross-reacted with neuronal tissue, becoming antineuronal antibodies [75-78]. The cross-reaction mechanism may lead to an exaggerated immune responsivity with pro-inflammatory cytokine production resulting in the damage to the structure of the central nervous system, which eventually results in neuropsychiatric disorders manifested by PANS patients. Contrary to Sydenham chorea, in which molecular mimicry has been widely demonstrated, molecular mechanisms in PANS still remain controversial. It was speculated that clarithromycin may act as an immunomodu- lator, downregulating the immune response and/or common hyper inflammation in PANS patients [79, 80]. The NMR analysis of urine after drug treatment highlighted the alteration of different metabolic pathways involved in the biosynthesis of proteins and energy production and in the synthesis of monoamine and amino acid neurotransmitters (tryptophan and phenylalanine). Aminoacyl-tRNA biosynthesis is a metabolic pathway characterized by a set of metabolites, including histidine, valine, lysine, isoleucine, proline, phenylalanine, tryptophan, and glutamine, which were altered in the urine following the therapy with clarithromycin. In particular, NMR analysis showed an increase in histidine/methylhistidine after drug treatment. Studies conducted on animal models indicated how the alteration of histidine carboxylase, which encodes the limiting enzyme in the histamine biosynthesis, led to an accumulation of histamine, with consequent increase of histidine in plasma and urine. Histamine is both a neurotransmitter and an immune modulator. Abnormalities in histaminergic signaling have been observed in diseases overlapping with PANS, such as Tourette syndrome [81-83]. Furthermore, it has been shown that the alteration of the levels of histamine in the central nervous system can lead to an altered immune response of the microglia cells, resulting in an excessive inflammatory response, which can induce neurodegenerative diseases, including PANS [75, 84-86, 88, 89]. Branched-chain amino acids (valine and isoleucine) and glutamine were found altered in the urine after antibiotic therapy. Some authors have emphasized the key role of branched-chain amino acids in the regulation of glutamate concentration in the central nervous system. Branched-chain amino acids are an important source of amino groups for the synthesis of brain glutamate and act like a "buffer system", avoiding the accumulation of glutamate. In fact, several neurological disorders are due to high concentrations of glutamate in the synapses [90-93]. The NMR analysis showed the alteration of different metabolites closely linked to the gut microbiota. Recent experimental data suggest a complex interaction between the gastrointestinal tract and central nervous system defined as the "gut-brain axis" [94, 95]. The development of gut microbiota immediately after birth is influenced by different genetic and non-genetic factors (e.g., maternal health, exposure to antibiotics, etc.), and seems to actively participate in the development of cognitive, emotional and behavioral processes immediately after birth. Studies on animal models have shown that altering the microbiota can significantly affect the concentration of the neurotransmitters, like serotonin in the hypothalamus, influencing several aspects of the development of the central nervous system [96-98]. PANS seems to be characterized by changes in the gut microbiota, providing some pathogenic organisms the opportunity to colonize the gut epithelium. Toxins produced by pathogenic organisms trigger an immune response in the host with consequent inflammation and increased gut permeability, determining the possible translocation of intestinal bacteria through the intestinal wall. The release of inflammatory cytokines may lead to the activation of neurons in the vagus nerve, modulating the activity of the central nervous system [99]. The analysis of urine after antibiotic therapy indicated the alteration of different metabolites, such as hippurate, methylamine, trimethylamine N-oxide and riboflavin, potentially linked to gut microbiota. Indeed, hippurate urinary levels are 
associated with the intestinal microbial profile as an indirect indicator of microbiota alterations. The administration of antibiotics induces the suppression of the gut microbiota and results in a reduction in the excretion of hippurate levels [54]. As already mentioned, Quagliarello et al., in a very recent work, highlighted the presence of a marked imbalance between Firmicutes and Bacteroidetes in a group of PANDAS patients compared to a control group [47]. Their results showed alterations of some metabolic pathways linked to inflammation, an increase in cellular metabolism and changes in riboflavin metabolism. In our case, an increase in the concentration of riboflavin after pharmacological treatment supported the hypothesis of the dysbiosis of the intestinal microflora.

\section{CONCLUSION AND PERSPECTIVES}

PANS is a clinical condition characterized by a sudden and dramatic OCD disorder with a recommended postinfectious immune-mediated etiology. The etiology and physiopathology of the disease are still largely unknown. The case of a 10-year-old girl with PANS was described before and after antibiotic treatment (clarithromycin). The main results of our study demonstratedthe alteration of several metabolic pathways concerning the microbial activity and the gut microbiota, highlighting its possible role in the development of PANS. Furthermore, different metabolic perturbations at the level of protein biosynthesis and energy metabolism were detected. Also, some amino acid metabolisms were altered, in particular, those of histidine, tryptophan and phenylalanine, which were directly linked to the brain function.

Based on our observations, we believe that metabolomics is a promising technology to unravel the mysteries of PANS in the near future.

\section{CONSENT FOR PUBLICATION}

Not applicable.

\section{FUNDING}

None.

\section{CONFLICT OF INTEREST}

The authors declare no conflict of interest, financial or otherwise.

\section{ACKNOWLEDGEMENTS}

Declared none.

\section{REFERENCES}

[1] Hesselmark E, Bejerot S. Patient Satisfaction and Treatments Offered to Swedish Patients with Suspected Pediatric Acute-Onset Neuropsychiatric Syndrome and Pediatric Autoimmune Neuropsychiatric Disorders Associated with Streptococcal Infections. J Child Adolesc Psychopharmacol 2019; 1-8. [http://dx.doi.org/10.1089/cap.2018.0141] [PMID: 31009235]

[2] Swedo SE, Leckman JF, Rose NR. From Research Subgroup to Clinical Syndrome: Modifying the PANDAS Criteria to Describe PANS (Pediatric Acute-onset Neuropsychiatric Syndrome). Pediatr Therapeut 2012; 2(2): 1-8. [http://dx.doi.org/10.4172/2161-0665.1000113]

[3] Thienemann M, Murphy T, Leckman J, et al. Clinical Management of Pediatric Acute-Onset Neuropsychiatric Syndrome: Part IPsychiatric and Behavioral Interventions. J Child Adolesc Psychopharmacol 2017; 27(7): 566-73.

[http://dx.doi.org/10.1089/cap.2016.0145] [PMID: 28722481]

[4] Chang K, Frankovich J, Cooperstock M, et al. PANS Collaborative Consortium. Clinical evaluation of youth with pediatric acute-onset neuropsychiatric syndrome (PANS): recommendations from the 2013 PANS Consensus Conference. J Child Adolesc Psychopharmacol 2015; 25(1): 3-13.

[http://dx.doi.org/10.1089/cap.2014.0084] [PMID: 25325534]

[5] Swedo SE, Leonard HL, Garvey M, et al. Pediatric autoimmune neuropsychiatric disorders associated with streptococcal infections: clinical description of the first 50 cases. Am J Psychiatry 1998; 155(2): 264-71.

[PMID: 9464208]

[6] Allen AJ, Leonard HL, Swedo SE. Case study: a new infectiontriggered, autoimmune subtype of pediatric OCD and Tourette's syndrome. J Am Acad Child Adolesc Psychiatry 1995; 34(3): 30711 .

[http://dx.doi.org/10.1097/00004583-199503000-00015] [PMID: 7896671]

[7] Garvey MA, Giedd J, Swedo SE. PANDAS: the search for environmental triggers of pediatric neuropsychiatric disorders. Lessons from rheumatic fever. J Child Neurol 1998; 13(9): 413-23. [http://dx.doi.org/10.1177/088307389801300901] [PMID: 9733286]

[8] Hoekstra PJ, Manson WL, Steenhuis MP, Kallenberg CGM, Minderaa RB. Association of common cold with exacerbations in pediatric but not adult patients with tic disorder: a prospective longitudinal study. J Child Adolesc Psychopharmacol 2005; 15(2): 285-92.

[http://dx.doi.org/10.1089/cap.2005.15.285] [PMID: 15910212]

[9] Murphy ML, Pichichero ME. Prospective identification and treatment of children with pediatric autoimmune neuropsychiatric disorder associated with group A streptococcal infection (PANDAS). Arch Pediatr Adolesc Med 2002; 156(4): 356-61.

[http://dx.doi.org/10.1001/archpedi.156.4.356] [PMID: 11929370]

[10] Müller N, Riedel M, Blendinger C, Oberle K, Jacobs E, AbeleHorn M. Mycoplasma pneumoniae infection and Tourette's syndrome. Psychiatry Res 2004; 129(2): 119-25.

[http://dx.doi.org/10.1016/j.psychres.2004.04.009] [PMID: 15590039]

Narita M. Pathogenesis of neurologic manifestations of Mycoplasma pneumoniae infection. Pediatr Neurol 2009; 41(3): 159-66. [http://dx.doi.org/10.1016/j.pediatrneurol.2009.04.012] [PMID: 19664529]

Molina V, Shoenfeld Y. Infection, vaccines and other environmental triggers of autoimmunity. Autoimmunity 2005; 38(3): 23545.

[http://dx.doi.org/10.1080/08916930500050277] [PMID:

16126512]

[13] Zibordi F, Zorzi G, Carecchio M, Nardocci N. CANS: Childhood acute neuropsychiatric syndromes. Eur J Paediatr Neurol 2018; 22(2): 316-20.

[http://dx.doi.org/10.1016/j.ejpn.2018.01.011] [PMID: 29398245]

[14] Swedo SE, Leonard HL, Rapoport JL. The pediatric autoimmune neuropsychiatric disorders associated with streptococcal infection (PANDAS) subgroup: separating fact from fiction. Pediatrics 2004; 113(4): 907-11.

[http://dx.doi.org/10.1542/peds.113.4.907] [PMID: 15060242]

[15] Kim SW, Grant JE, Kim SI, et al. A possible association of recurrent streptococcal infections and acute onset of obsessivecompulsive disorder. J Neuropsychiatry Clin Neurosci 2004; 16(3): 252-60.

[http://dx.doi.org/10.1176/jnp.16.3.252] [PMID: 15377732]

[16] Yavlovich A, Tarshis M, Rottem S. Internalization and intracellular survival of Mycoplasma pneumoniae by non-phagocytic cells. FEMS Microbiol Lett 2004; 233(2): 241-6.

[http://dx.doi.org/10.1111/j.1574-6968.2004.tb09488.x] [PMID: 15063492]

[17] Sánchez-Vargas FM, Gómez-Duarte OG. Mycoplasma pneumoniae-an emerging extra-pulmonary pathogen. Clin Microbiol Infect 2008; 14(2): 105-17. 
[http://dx.doi.org/10.1111/j.1469-0691.2007.01834.x] [PMID: 17949442]

[18] Narita M. Classification of Extrapulmonary Manifestations Due to Mycoplasma pneumoniae Infection on the Basis of Possible Pathogenesis. Front Microbiol 2016; 7: 23.

[http://dx.doi.org/10.3389/fmicb.2016.00023] [PMID: 26858701]

[19] Yang J, Hooper WC, Phillips DJ, Talkington DF. Cytokines in Mycoplasma pneumoniae infections. Cytokine Growth Factor Rev 2004; 15(2-3): 157-68.

[http://dx.doi.org/10.1016/j.cytogfr.2004.01.001] [PMID: 15110799]

[20] Meseguer MA, Alvarez A, Rejas MT, Sánchez C, Pérez-Díaz JC, Baquero F. Mycoplasma pneumoniae: a reduced-genome intracellular bacterial pathogen. Infect Genet Evol 2003; 3(1): 47-55. [http://dx.doi.org/10.1016/S1567-1348(02)00151-X] [PMID: 12797972]

[21] Kuwahara M, Samukawa M, Ikeda T, et al. Characterization of the neurological diseases associated with Mycoplasma pneumoniae infection and anti-glycolipid antibodies. J Neurol 2017; 264(3): 46775.

[http://dx.doi.org/10.1007/s00415-016-8371-1] [PMID: 28025664]

[22] Bitnun A, Ford-Jones EL, Petric M, et al. Acute childhood encephalitis and Mycoplasma pneumoniae. Clin Infect Dis 2001; 32(12): 1674-84.

[http://dx.doi.org/10.1086/320748] [PMID: 11360206]

[23] Hynson JL, Kornberg AJ, Coleman LT, Shield L, Harvey AS, Kean MJ. Clinical and neuroradiologic features of acute disseminated encephalomyelitis in children. Neurology 2001; 56(10): 1308-12. [http://dx.doi.org/10.1212/WNL.56.10.1308] [PMID: 11376179]

[24] Esposito S, Di Pietro GM, Madini B, Mastrolia MV, Rigante D. A spectrum of inflammation and demyelination in acute disseminated encephalomyelitis (ADEM) of children. Autoimmun Rev 2015; 14(10): 923-9.

[http://dx.doi.org/10.1016/j.autrev.2015.06.002] [PMID: 26079482]

[25] Kornreich L, Shkalim-Zemer V, Levinsky Y, Abdallah W, Ganelin-Cohen E, Straussberg R. Acute Cerebellitis in Children: A Many-Faceted Disease. J Child Neurol 2016; 31(8): 991-7. [http://dx.doi.org/10.1177/0883073816634860] [PMID: 26961264]

[26] Schneider T, Thomalla G, Goebell E, Piotrowski A, Yousem DM. Magnetic resonance imaging findings in patients presenting with (sub)acute cerebellar ataxia. Neuroradiology 2015; 57(6): 551-9. [http://dx.doi.org/10.1007/s00234-015-1496-6] [PMID: 25686577]

[27] Diaco M, Ancarini F, Montalto M, et al. Association of myasthenia gravis and antisynthetase syndrome: a case report. Int J Immunopathol Pharmacol 2004; 17(3): 395-9.

[http://dx.doi.org/10.1177/039463200401700320] [PMID: 15461874]

[28] Tay CG, Fong CY, Ong LC. Transient parkinsonism following mycoplasma pneumoniae infection with normal brain magnetic resonance imaging (MRI). J Child Neurol 2014; 29(12): NP193-5. [http://dx.doi.org/10.1177/0883073813510741] [PMID: 24309239]

[29] Müller N, Riedel M, Förderreuther S, Blendinger C, Abele-Horn M. Tourette's syndrome and mycoplasma pneumoniae infection. Am J Psychiatry 2000; 157(3): 481-2.

[http://dx.doi.org/10.1176/appi.ajp.157.3.481-a] [PMID: 10698843]

[30] Williams KA, Swedo SE. Post-infectious autoimmune disorders: Sydenham's chorea, PANDAS and beyond. Brain Res 2015; 1617: 144-54.

[http://dx.doi.org/10.1016/j.brainres.2014.09.071] [PMID: 25301689]

[31] Spinello C, Laviola G, Macrì S. Pediatric Autoimmune Disorders Associated with Streptococcal Infections and Tourette's Syndrome in Preclinical Studies. Front Neurosci 2016; 10: 310 [http://dx.doi.org/10.3389/fnins.2016.00310] [PMID: 27445678]

[32] Kirvan CA, Swedo SE, Snider LA, Cunningham MW. Antibodymediated neuronal cell signaling in behavior and movement disorders. J Neuroimmunol 2006; 179(1-2): 173-9.

[http://dx.doi.org/10.1016/j.jneuroim.2006.06.017] [PMID: 16875742]

[33] Lotan D, Benhar I, Alvarez K, et al. Behavioral and neural effects of intra-striatal infusion of anti-streptococcal antibodies in rats. Brain Behav Immun 2014; 38: 249-62.

[http://dx.doi.org/10.1016/j.bbi.2014.02.009] [PMID: 24561489]
[34] Kirvan CA, Swedo SE, Heuser JS, Cunningham MW. Mimicry and autoantibody-mediated neuronal cell signaling in Sydenham chorea. Nat Med 2003; 9(7): 914-20.

[http://dx.doi.org/10.1038/nm892] [PMID: 12819778]

[35] Calaprice D, Tona J, Murphy TK. Treatment of Pediatric AcuteOnset Neuropsychiatric Disorder in a Large Survey Population. J Child Adolesc Psychopharmacol 2018; 28(2): 92-103.

[http://dx.doi.org/10.1089/cap.2017.0101] [PMID: 28832181]

[36] Walls A, Cubangbang M, Wang H, et al. Pediatric Autoimmune Neuropsychiatric Disorder Associated with Streptococcus Immunology: A Pilot Study. Otolaryngol Head Neck Surg 2015; 153(1): 130-6.

[http://dx.doi.org/10.1177/0194599815577784] [PMID: 25832830]

[37] Dileepan T, Linehan JL, Moon JJ, Pepper M, Jenkins MK, Cleary PP. Robust antigen specific th $17 \mathrm{~T}$ cell response to group A Streptococcus is dependent on IL-6 and intranasal route of infection. PLoS Pathog 2011; 7(9)e1002252

[http://dx.doi.org/10.1371/journal.ppat.1002252] [PMID:

21966268]

[38] Dileepan T, Smith ED, Knowland D, et al. Group A Streptococcus intranasal infection promotes CNS infiltration by streptococcalspecific Th17 cells. J Clin Invest 2016; 126(1): 303-17. [http://dx.doi.org/10.1172/JCI80792] [PMID: 26657857]

[39] Clapp M, Aurora N, Herrera L, Bhatia M, Wilen E, Wakefield S. Gut microbiota's effect on mental health: The gut-brain axis. Clin Pract 2017; 7(4): 987.

[http://dx.doi.org/10.4081/cp.2017.987] [PMID: 29071061]

[40] Carabotti M, Scirocco A, Maselli MA, Severi C. The gut-brain axis: interactions between enteric microbiota, central and enteric nervous systems. Ann Gastroenterol 2015; 28(2): 203-9. [PMID: 25830558]

[41] Foster JA, McVey Neufeld KA. Gut-brain axis: how the microbiome influences anxiety and depression. Trends Neurosci 2013; 36(5): 305-12.

[http://dx.doi.org/10.1016/j.tins.2013.01.005] [PMID: 23384445]

[42] Karlsson F, Tremaroli V, Nielsen J, Bäckhed F. Assessing the human gut microbiota in metabolic diseases. Diabetes 2013; 62(10): 3341-9.

[http://dx.doi.org/10.2337/db13-0844] [PMID: 24065795]

[43] Putignani L, Del Chierico F, Vernocchi P, Cicala M, Cucchiara S, Dallapiccola B. Dysbiotrack Study Group. Gut Microbiota Dysbiosis as Risk and Premorbid Factors of IBD and IBS Along the Childhood-Adulthood Transition. Inflamm Bowel Dis 2016; 22(2): 487-504.

[http://dx.doi.org/10.1097/MIB.0000000000000602] [PMID: 26588090]

[44] Li Q, Zhou JM. The microbiota-gut-brain axis and its potential therapeutic role in autism spectrum disorder. Neuroscience 2016; 324: $131-9$.

[http://dx.doi.org/10.1016/j.neuroscience.2016.03.013] [PMID: 26964681]

[45] Rachid R, Chatila TA. The role of the gut microbiota in food allergy. Curr Opin Pediatr 2016; 28(6): 748-53.

[http://dx.doi.org/10.1097/MOP.0000000000000427] [PMID 27749359]

[46] Biesmans S, Bouwknecht JA, Ver Donck L, et al. Peripheral Administration of Tumor Necrosis Factor-Alpha Induces Neuroinflammation and Sickness but Not Depressive-Like Behavior in Mice. BioMed Res Int 2015; 2015716920

[http://dx.doi.org/10.1155/2015/716920] [PMID: 26290874]

[47] Quagliariello A, Del Chierico F, Russo A, et al. Gut Microbiota Profiling and Gut-Brain Crosstalk in Children Affected by Pediatric Acute-Onset Neuropsychiatric Syndrome and Pediatric Autoimmune Neuropsychiatric Disorders Associated With Streptococcal Infections. Front Microbiol 2018; 9: 675.

[http://dx.doi.org/10.3389/fmicb.2018.00675] [PMID: 29686658]

[48] Sethi S, Brietzke E. Omics-Based Biomarkers: Application of Metabolomics in Neuropsychiatric Disorders. Int J Neuropsychopharmacol 2015; 19(3)pyv096 [http://dx.doi.org/10.1093/ijnp/pyv096] [PMID: 26453695]

[49] Aronson JK. Biomarkers and surrogate endpoints. Br J Clin Pharmacol 2005; 59(5): 491-4.

[http://dx.doi.org/10.1111/j.1365-2125.2005.02435.x] [PMID: 15842546]

[50] Strimbu K, Tavel JA. What are biomarkers? Curr Opin HIV AIDS 2010; 5(6): 463-6. 
[http://dx.doi.org/10.1097/COH.0b013e32833ed177] [PMID: 20978388]

[51] Fanos V, Van den Anker J, Noto A, Mussap M, Atzori L. Metabolomics in neonatology: fact or fiction? Semin Fetal Neonatal Med 2013; 18(1): 3-12.

[http://dx.doi.org/10.1016/j.siny.2012.10.014] [PMID: 23195852]

[52] Oliver SG, Winson MK, Kell DB, Baganz F. Systematic functional analysis of the yeast genome. Trends Biotechnol 1998; 16(9): 3738.

[http://dx.doi.org/10.1016/S0167-7799(98)01214-1] [PMID: 9744112]

[53] Noto A, Fanos V, Barberini L, et al. The urinary metabolomics profile of an Italian autistic children population and their unaffected siblings. J Matern Fetal Neonatal Med 2014; 27(Suppl. 2): 46-52.

[http://dx.doi.org/10.3109/14767058.2014.954784] [PMID: 25284177]

[54] Yap IKS, Angley M, Veselkov KA, Holmes E, Lindon JC, Nicholson JK. Urinary metabolic phenotyping differentiates children with autism from their unaffected siblings and age-matched controls. J Proteome Res 2010; 9(6): 2996-3004.

[http://dx.doi.org/10.1021/pr901188e] [PMID: 20337404]

[55] Shaw W. Increased urinary excretion of a 3-(3-hydroxyphenyl)-3hydroxypropionic acid (HPHPA), an abnormal phenylalanine metabolite of Clostridia spp. in the gastrointestinal tract, in urine samples from patients with autism and schizophrenia. Nutr Neurosci 2010; 13(3): 135-43.

[http://dx.doi.org/10.1179/147683010X12611460763968] [PMID: 20423563]

[56] Lussu M, Noto A, Masili A, et al. The urinary ${ }^{1}$ H-NMR metabolomics profile of an italian autistic children population and their unaffected siblings. Autism Res 2017; 10(6): 1058-66. [http://dx.doi.org/10.1002/aur.1748] [PMID: 28296209]

[57] van De Sande MMH, van Buul VJ, Brouns FJPH. Autism and nutrition: the role of the gut-brain axis. Nutr Res Rev 2014; 27(2): 199-214.

[http://dx.doi.org/10.1017/S0954422414000110] [PMID: 25004237]

[58] Murgia F, Svegliati S, Poddighe S, et al. Metabolomic profile of systemic sclerosis patients. Sci Rep 2018; 8(1): 7626. [http://dx.doi.org/10.1038/s41598-018-25992-7] [PMID: 29769578]

[59] Lorefice L, Murgia F, Fenu G, et al. Assessing the Metabolomic Profile of Multiple Sclerosis Patients Treated with Interferon Beta 1a by 1H-NMR Spectroscopy Neurother J Am Soc Exp Neurother 2019.

[60] Fiandaca MS, Gross TJ, Johnson TM, et al. Potential Metabolomic Linkage in Blood between Parkinson's Disease and Traumatic Brain Injury. Metabolites 2018; 8(3): E50. [http://dx.doi.org/10.3390/metabo8030050] [PMID: 30205491]

[61] Wilbur C, Bitnun A, Kronenberg S, et al. PANDAS/PANS in childhood: Controversies and evidence. Paediatr Child Health 2019; 24(2): 85-91.

[http://dx.doi.org/10.1093/pch/pxy145] [PMID: 30996598 ]

[62] Malz F, Jancke H. . Validation of quantitative NMR, J Pharm Biomed Anal 2005; 10; 38(5): 813-23.

[63] Xia J, Wishart DS. Web-based inference of biological patterns, functions and pathways from metabolomic data using MetaboAnalyst. Nat Protoc 2011; 6(6): 743-60.

[http://dx.doi.org/10.1038/nprot.2011.319] [PMID: 21637195]

[64] Toufexis MD, Hommer R, Gerardi DM, et al. Disordered eating and food restrictions in children with PANDAS/PANS. J Child Adolesc Psychopharmacol 2015; 25(1): 48-56.

[http://dx.doi.org/10.1089/cap.2014.0063] [PMID: 25329522]

[65] Ercan TE, Ercan G, Severge B, Arpaozu M, Karasu G. Mycoplasma pneumoniae infection and obsessive-compulsive disease: a case report. J Child Neurol 2008; 23(3): 338-40. [http://dx.doi.org/10.1177/0883073807308714] [PMID: 18079308]

[66] Budman CL, Kerjakovic M, Bruun RD. Viral infection and tic exacerbation. J Am Acad Child Adolesc Psychiatry 1997; 36(2): 162 .

[http://dx.doi.org/10.1097/00004583-199702000-00004] [PMID: 9031566]

[67] Garnier J-M, Noël G, Retornaz K, Blanc P, Minodier P. Extrapulmonary infections due to Mycoplasma pneumoniae. Arch Pediatr Organe Off Soc Francaise Pediatr 2005; 12(Suppl. 1): S2-6.
[68] Halbedel S, Hames C, Stülke J. Regulation of carbon metabolism in the mollicutes and its relation to virulence. J Mol Microbiol Biotechnol 2007; 12(1-2): 147-54.

[http://dx.doi.org/10.1159/000096470] [PMID: 17183222]

[69] Pollack JD, Myers MA, Dandekar T, Herrmann R. Suspected utility of enzymes with multiple activities in the small genome Mycoplasma species: the replacement of the missing "household" nucleoside diphosphate kinase gene and activity by glycolytic kinases. OMICS 2002; 6(3): 247-58.

[http://dx.doi.org/10.1089/15362310260256909] [PMID: 12427276]

[70] Morozumi M, Hasegawa K, Kobayashi R, et al. Emergence of macrolide-resistant Mycoplasma pneumoniae with a 23S rRNA gene mutation. Antimicrob Agents Chemother 2005; 49(6): 2302-6. [http://dx.doi.org/10.1128/AAC.49.6.2302-2306.2005] [PMID: 15917525]

[71] Cao B, Zhao CJ, Yin YD, et al. High prevalence of macrolide resistance in Mycoplasma pneumoniae isolates from adult and adolescent patients with respiratory tract infection in China. Clin Infect Dis 2010; 51(2): 189-94.

[http://dx.doi.org/10.1086/653535] [PMID: 20540621]

[72] Goldstein BI, Kemp DE, Soczynska JK, McIntyre RS. Inflammation and the phenomenology, pathophysiology, comorbidity, and treatment of bipolar disorder: a systematic review of the literature. J Clin Psychiatry 2009; 70(8): 1078-90.

[http://dx.doi.org/10.4088/JCP.08r04505] [PMID: 19497250]

[73] Potvin S, Stip E, Sepehry AA, Gendron A, Bah R, Kouassi E. Inflammatory cytokine alterations in schizophrenia: a systematic quantitative review. Biol Psychiatry 2008; 63(8): 801-8. [http://dx.doi.org/10.1016/j.biopsych.2007.09.024] [PMID: 18005941]

[74] Mitchell RHB, Goldstein BI. Inflammation in children and adolescents with neuropsychiatric disorders: a systematic review. J Am Acad Child Adolesc Psychiatry 2014; 53(3): 274-96.

[http://dx.doi.org/10.1016/j.jaac.2013.11.013] [PMID: 24565356]

[75] Kumar A, Williams MT, Chugani HT. Evaluation of basal ganglia and thalamic inflammation in children with pediatric autoimmune neuropsychiatric disorders associated with streptococcal infection and tourette syndrome: a positron emission tomographic (PET) study using 11C-[R]-PK11195. J Child Neurol 2015; 30(6): 74956.

[http://dx.doi.org/10.1177/0883073814543303] [PMID: 25117419]

[76] Church AJ, Cardoso F, Dale RC, Lees AJ, Thompson EJ, Giovannoni G. Anti-basal ganglia antibodies in acute and persistent Sydenham's chorea. Neurology 2002; 59(2): 227-31.

[http://dx.doi.org/10.1212/WNL.59.2.227] [PMID: 12136062]

[77] Schrag A, Gilbert R, Giovannoni G, Robertson MM, Metcalfe C, Ben-Shlomo Y. Streptococcal infection, Tourette syndrome, and OCD: is there a connection? Neurology 2009; 73(16): 1256-63. [http://dx.doi.org/10.1212/WNL.0b013e3181bd10fd] [PMID: 19794128]

[78] Singer HS, Hong JJ, Yoon DY, Williams PN. Serum autoantibodies do not differentiate PANDAS and Tourette syndrome from controls. Neurology 2005; 65(11): 1701-7.

[http://dx.doi.org/10.1212/01.wnl.0000183223.69946.f1] [PMID: 16207842]

[79] Mohammad SS, Dale RC. Principles and approaches to the treatment of immune-mediated movement disorders. Eur J Paediatr Neurol 2018; 22(2): 292-300.

[http://dx.doi.org/10.1016/j.ejpn.2017.11.010] [PMID: 29289523]

[80] Kanoh S, Rubin BK. Mechanisms of action and clinical application of macrolides as immunomodulatory medications. Clin Microbiol Rev 2010; 23(3): 590-615.

[http://dx.doi.org/10.1128/CMR.00078-09] [PMID: 20610825]

[81] Baldan LC, Williams KA, Gallezot J-D, et al. Histidine decarboxylase deficiency causes tourette syndrome: parallel findings in humans and mice. Neuron 2014; 81(1): 77-90.

[http://dx.doi.org/10.1016/j.neuron.2013.10.052] [PMID:

24411733]

[82] Ercan-Sencicek AG, Stillman AA, Ghosh AK, et al. L-histidine decarboxylase and Tourette's syndrome. N Engl J Med 2010; 362(20): 1901-8.

[http://dx.doi.org/10.1056/NEJMoa0907006] [PMID: 20445167]

[83] Panula P, Nuutinen S. The histaminergic network in the brain: basic organization and role in disease. Nat Rev Neurosci 2013; 14(7): 472-87. 
[http://dx.doi.org/10.1038/nrn3526] [PMID: 23783198]

[84] Rocha SM, Pires J, Esteves M, Graça B, Bernardino L. Histamine: a new immunomodulatory player in the neuron-glia crosstalk. Front Cell Neurosci 2014; 8: 120.

[http://dx.doi.org/10.3389/fncel.2014.00120] [PMID: 24817841]

[85] Ferreira R, Santos T, Gonçalves J, et al. Histamine modulates microglia function. J Neuroinflammation 2012; 9: 90

[http://dx.doi.org/10.1186/1742-2094-9-90] [PMID: 22569158]

[86] Frick LR, Williams K, Pittenger C. Microglial dysregulation in psychiatric disease. Clin Dev Immunol 2013; 2013608654 [http://dx.doi.org/10.1155/2013/608654] [PMID: 23690824]

[87] Frick L, Rapanelli M, Abbasi E, Ohtsu H, Pittenger C. Histamine regulation of microglia: Gene-environment interaction in the regulation of central nervous system inflammation. Brain Behav Immun 2016; 57: 326-37. [http://dx.doi.org/10.1016/j.bbi.2016.07.002] [PMID: 27381299]

[88] van Wamelen DJ, Shan L, Aziz NA, et al. Functional increase of brain histaminergic signaling in Huntington's disease. Brain Pathol 2011; 21(4): 419-27.

[http://dx.doi.org/10.1111/j.1750-3639.2010.00465.x] [PMID: 21106039]

[89] John J, Thannickal TC, McGregor R, et al. Greatly increased numbers of histamine cells in human narcolepsy with cataplexy. Ann Neurol 2013; 74(6): 786-93.

[http://dx.doi.org/10.1002/ana.23968] [PMID: 23821583]

[90] Yudkoff M. Interactions in the Metabolism of Glutamate and the Branched-Chain Amino Acids and Ketoacids in the CNS. Neurochem Res 2017; 42(1): 10-8.

[http://dx.doi.org/10.1007/s11064-016-2057-z] [PMID: 27696119]

[92] García-Espinosa MA, Wallin R, Hutson SM, Sweatt AJ. Widespread neuronal expression of branched-chain aminotransferase in the CNS: implications for leucine/glutamate metabolism and for signaling by amino acids. J Neurochem 2007; 100(6): 1458-68. [http://dx.doi.org/10.1111/j.1471-4159.2006.04332.x] [PMID: 17348860]
[92] Hull J, Hindy ME, Kehoe PG, Chalmers K, Love S, Conway ME. Distribution of the branched chain aminotransferase proteins in the human brain and their role in glutamate regulation. J Neurochem 2012; 123(6): 997-1009.

[http://dx.doi.org/10.1111/jnc.12044] [PMID: 23043456]

[93] Sweatt AJ, Garcia-Espinosa MA, Wallin R, Hutson SM. Branchedchain amino acids and neurotransmitter metabolism: expression of cytosolic branched-chain aminotransferase (BCATc) in the cerebellum and hippocampus. J Comp Neurol 2004; 477(4): 360-70.

[http://dx.doi.org/10.1002/cne.20200] [PMID: 15329886]

[94] Mayer EA, Tillisch K, Gupta A. Gut/brain axis and the microbiota. J Clin Invest 2015; 125(3): 926-38.

[http://dx.doi.org/10.1172/JCI76304] [PMID: 25689247]

[95] Yarandi SS, Peterson DA, Treisman GJ, Moran TH, Pasricha PJ. Modulatory Effects of Gut Microbiota on the Central Nervous System: How Gut Could Play a Role in Neuropsychiatric Health and Diseases. J Neurogastroenterol Motil 2016; 22(2): 201-12. [http://dx.doi.org/10.5056/jnm15146] [PMID: 27032544]

[96] Carabotti M, Scirocco A, Maselli MA, Severi C. The gut-brain axis: interactions between enteric microbiota, central and enteric nervous systems. Ann Gastroenterol 2015; 28(2): 203-9. [PMID: 25830558]

[97] Palmer C, Bik EM, DiGiulio DB, Relman DA, Brown PO. Development of the human infant intestinal microbiota. PLoS Biol 2007; 5(7) 177

[http://dx.doi.org/10.1371/journal.pbio.0050177] [PMID: 17594176]

[98] Wikoff WR, Anfora AT, Liu J, et al. Metabolomics analysis reveals large effects of gut microflora on mammalian blood metabolites. Proc Natl Acad Sci USA 2009; 106(10): 3698-703. [http://dx.doi.org/10.1073/pnas.0812874106] [PMID: 19234110]

[99] Gareau MG, Silva MA, Perdue MH. Pathophysiological mechanisms of stress-induced intestinal damage. Curr Mol Med 2008; 8(4): $274-81$

[http://dx.doi.org/10.2174/156652408784533760] [PMID: 18537635]

DISCLAIMER: The above article has been published in Epub (ahead of print) on the basis of the materials provided by the author. The Editorial Department reserves the right to make minor modifications for further improvement of the manuscript. 